\title{
Cyclic Flexural Behavior of Reinforced Concrete Beams
}

\author{
Prafulla B MALLA ${ }^{1}$, Hong $\mathrm{ZHOU}^{2}$, Yi CHE ${ }^{1}$ \\ ${ }^{1}$ State Key Laboratory of Costal and Offshore Engineering, Dalian University of Technology, Dalian, Liaoning 116024, China \\ ${ }^{2}$ Department of Architectural Engineering, Shandong Water Conservancy Vocational College, Rizhao, Shandong Code, China
}

\begin{abstract}
The present study aims at investigating the cyclic flexural behavior of reinforced concrete beams with varying depths. Five reinforced concrete beams with beam depth ranging from $250 \mathrm{~mm}$ to $750 \mathrm{~mm}$ were tested under reversed cyclic loading and the influence of beam depth on the flexural strength and ductility of reinforced concrete beams was investigated. In addition, OpenSees was used to model the test specimens and the analytical results were compared with the experimental reuslts. It is shown that there is no apparent size effect on the normalized ultimate flexural strength of the tested beams, while for the displacement ductility factor, a significant size effect is observed. Load-deflection hysteric curves of test specimens obtained by the fiber-based element of OpenSees with Concrete03 and Hysteric models are in good agreement with those from experimental tests.
\end{abstract}

\section{Introduction}

The size effect has been experimentally evidenced for most brittle types of failures of plain and reinforced concrete members, for example, shear and torsional failure of beams, punching shear failure of slabs and pullout failure of bars etc. $[1,2]$. In addition, the effect of size on flexural behavior of reinforced concrete beams was also investigated [3-9]. Early work on flexural behavior of reinforced concrete beams indicated that there was no apparent size effect on flexural strength and rotational capacity [3, 4]. Appa et al. [5] and Yi et al. [6] reported from their studies that size effect is significant for both flexural strength and ductility. Most of the research on under-reinforced concrete beams confirmed the existence of size effect on rotational capacity [7-9]. Some researchers also investigated behavior of over-reinforced and prestressed concrete beams failing due to concrete compressive failure and found that significant size effect on rotational capacity or ductility of beams exists [10-12].

However, most of the studies reported in the literature are concerned with the size effect of flexural behavior of reinforced concrete beams that contain only tensile reinforcement and are subjected to monotonic loading. In reinforced concrete moment-resistance frames, the cross section of the beam end to resist the positive and negative moment induced by lateral earthquake and vertical loads, locates in the potential plastic hinge region where sufficient ductility and rotational capacity is required. Therefore, a better understanding of size effect on flexural behavior of doubly reinforced concrete beams subjected to cyclic loading is necessary to ensure the safety of reinforced concrete structures.

In view of this, the influence of beam depth on the cyclic flexural behavior of RC beams was investigated experimentally in this study. Besides, nonlinear analysis of test specimens was carried out using OpenSees models.

\section{Experimental Program}

\subsection{Test Specimens and Material Properties}

In total, five specimens with beam depth ranging from 250 $\mathrm{mm}$ to $750 \mathrm{~mm}$ were tested under reversed cyclic loading. The specimens used in the experimental program consisted of two beam elements with identical section cast integrally with a stub as the column element at mid-span. The details of specimens are shown in figure 1 and table 1 .

All specimens were cast from the same batch of concrete supplied by a local ready-mix plant. Concrete cubes of $150 \times 150 \times 150 \mathrm{~mm}^{3}$ were casted along with the specimens, and compressive strength tests were performed at time of cyclic loading tests. Hot-rolled deformed bars with diameters of $12,20,22$ and $25 \mathrm{~mm}$ were used as longitudinal reinforcement giving longitudinal reinforcement ratios of $1.08 \%$ and $0.69 \%$, respectively. Hot-rolled plain bars with 6,8 and $10 \mathrm{~mm}$ diameters were used as vertical stirrups, with a constant transverse reinforcement ratio equal to $0.52 \%$. Properties of steel bars are presented in table 2 .

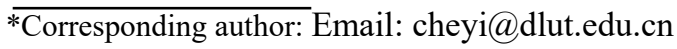




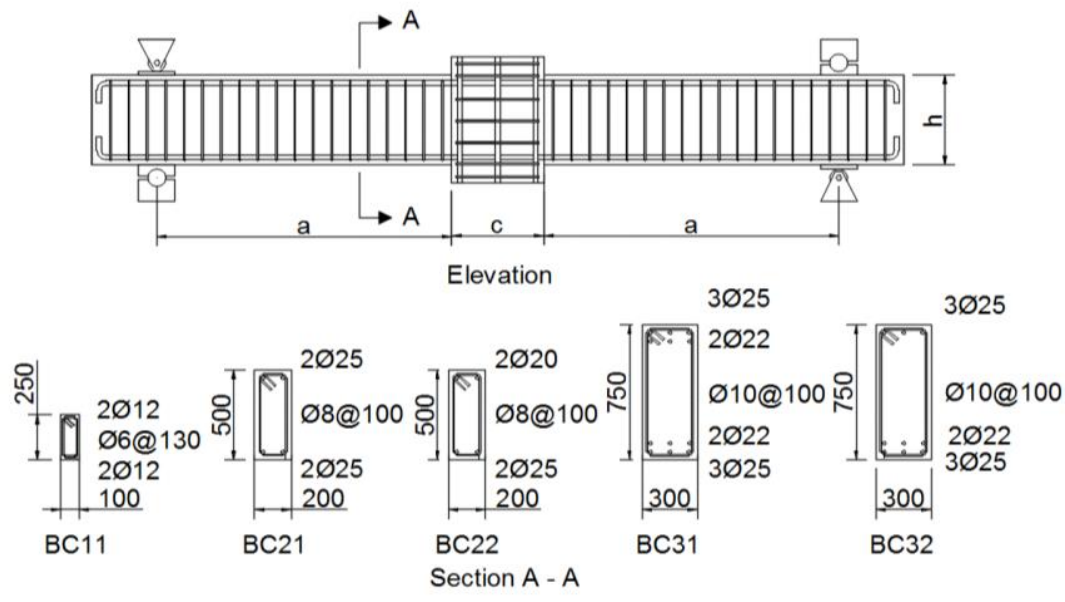

Figure 1 Details of test specimens $(\mathrm{mm})$

Table 1 Parameters of specimens

\begin{tabular}{|c|c|c|c|c|c|c|c|c|}
\hline \multirow[b]{2}{*}{ Specimen } & \multicolumn{4}{|c|}{ Dimension $(\mathrm{mm})$} & \multirow{2}{*}{$\begin{array}{l}\text { Concrete cubic } \\
\text { strength } \mathrm{f}_{\mathrm{cu}} \\
(\mathrm{MPa})\end{array}$} & \multicolumn{2}{|c|}{ Longitudinal rebar ratio (\%) } & \multirow{2}{*}{$\begin{array}{c}\text { Stirrup } \\
\text { ratio } \\
\rho_{\mathrm{sv}}(\%)\end{array}$} \\
\hline & Width b & Depth d & $\begin{array}{l}\text { Effective } \\
\text { depth } d_{0}\end{array}$ & $\begin{array}{c}\text { Span } \\
\text { a }\end{array}$ & & Top bar $\rho_{\mathrm{s}}$ & $\begin{array}{c}\text { Bottom bar } \\
\rho_{\mathrm{s}^{\prime}}\end{array}$ & \\
\hline BC11 & 100 & 250 & 210 & 3 & 73.6 & 1.08 & 1.08 & 0.52 \\
\hline $\mathrm{BC} 21$ & 200 & 500 & 456 & 3 & 73.8 & 1.08 & 1.08 & 0.52 \\
\hline BC31 & 300 & 750 & 688 & 3 & 72.0 & 1.08 & 1.08 & 0.52 \\
\hline $\mathrm{BC} 22$ & 200 & 500 & 456 & 3 & 73.8 & 1.08 & 0.69 & 0.52 \\
\hline BC32 & 300 & 750 & 688 & 3 & 72.0 & 1.08 & 0.69 & 0.52 \\
\hline
\end{tabular}

Table 2 Properties of steel bars

\begin{tabular}{ccc}
\hline $\begin{array}{c}\text { Diameter of steel bar } \\
(\mathrm{mm})\end{array}$ & $\begin{array}{c}\text { Yield strength } \\
(\mathrm{MPa})\end{array}$ & Tensile strength (MPa) \\
\hline 6 & 407 & 578 \\
8 & 467 & 507 \\
10 & 384 & 535 \\
12 & 420 & 618 \\
22 & 423 & 598 \\
25 & 470 & 660 \\
\hline
\end{tabular}

\subsection{Loading Protocol and Test Setup}

Figure 2 shows the planned loading protocol for the reversed cyclic loading test. Each specimen was subjected to progressively increasing load cycles. After yielding of tensile reinforcement, progressively increasing displacement cycles were applied until the specimen failed completely. For each displacement step, three fully reversed cycles were applied. The test setup is shown in figure 3 .

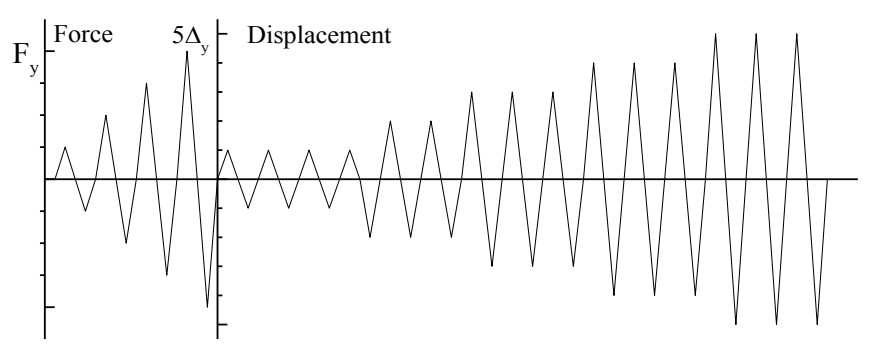

Figure 2 Loading protocol

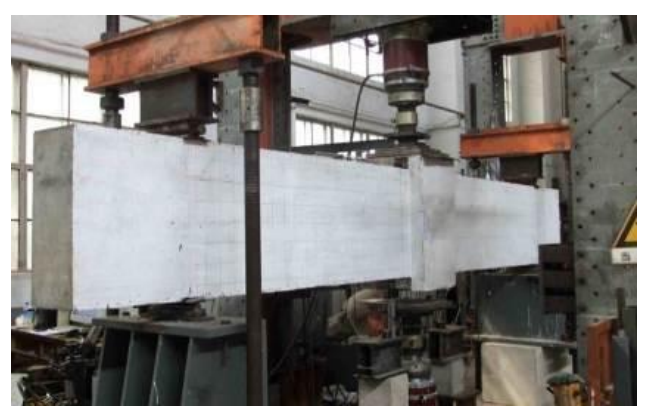

Figure 3 Test setup 
Similar failure patterns were also observed in other specimens regardless of specimen sizes. Flexural cracks were firstly observed at sections adjacent to the central stub. The failure of the specimen resulted from the yielding of tensile reinforcement followed by the crushing of concrete. Figure 4 shows the typical failure patterns of Specimens BC11, BC21 and BC31 at the end of the test.

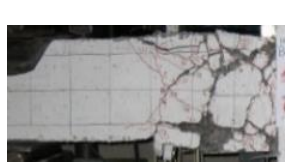

(a) Specimen BC11

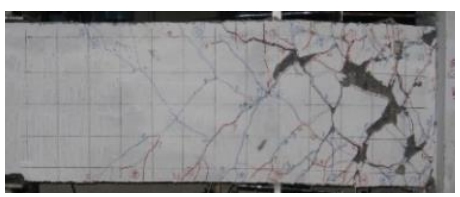

(b) Specimen BC21

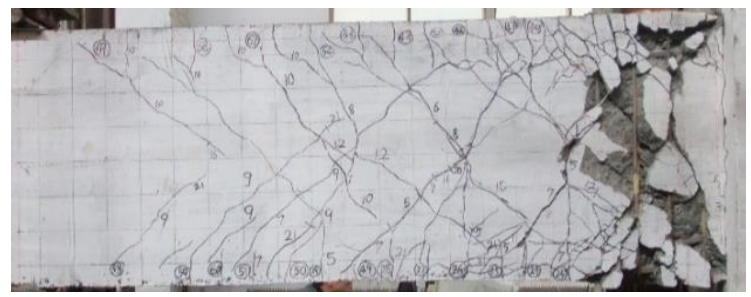

(c) Specimen BC31

Figure 4 Failure patterns of specimens

\subsection{Test Results}

Test results are listed in table 3, in which the ductility factor for each specimen is calculated by

$$
\mu=\Delta \mathrm{u} / \Delta \mathrm{y}
$$

Where $\mu$ is the displacement ductility factor, and $\Delta y$ and $\Delta \mathrm{u}$ are displacements at yield load and ultimate load, respectively.

Table 3 Experimental results

\begin{tabular}{|c|c|c|c|c|c|c|}
\hline \multirow[b]{2}{*}{ Specimen } & \multirow[b]{2}{*}{ Loading direction } & \multicolumn{2}{|c|}{ At yield } & \multicolumn{2}{|c|}{ At ultimate } & \multirow[b]{2}{*}{ Ductility factor $\mu$} \\
\hline & & Moment My $[\mathrm{kN} . \mathrm{m}]$ & $\begin{array}{c}\text { Displacement } \\
\Delta \mathrm{y}[\mathrm{mm}]\end{array}$ & $\begin{array}{c}\text { Moment } \\
\mathrm{Mu}[\mathrm{kN} . \mathrm{m}]\end{array}$ & $\begin{array}{c}\text { Displacement } \\
\Delta \mathrm{u}[\mathrm{mm}]\end{array}$ & \\
\hline \multirow{2}{*}{$\mathrm{BC} 11$} & + & 17.46 & 3.32 & 20.12 & 29.23 & 8.80 \\
\hline & - & 17.42 & 3.00 & 20.29 & - & - \\
\hline \multirow{2}{*}{$\mathrm{BC} 21$} & + & 194.14 & 7.55 & 235.48 & 43.46 & 5.76 \\
\hline & - & 192.30 & 7.62 & 223.43 & - & - \\
\hline \multirow{2}{*}{$\mathrm{BC} 31$} & + & 656.43 & 13.01 & 754.49 & 65.11 & 5.00 \\
\hline & - & 652.31 & 19.03 & 752.41 & - & - \\
\hline \multirow{2}{*}{$\mathrm{BC} 22$} & + & 190.05 & 8.97 & 236.00 & 46.83 & 5.22 \\
\hline & - & 114.70 & 4.66 & 137.68 & - & - \\
\hline \multirow{2}{*}{$\mathrm{BC} 32$} & + & 662.22 & 12.24 & 779.62 & 59.16 & 4.83 \\
\hline & - & 481.04 & 9.40 & 533.01 & - & - \\
\hline
\end{tabular}

\subsection{Size Effect}

The normalized flexural ultimate strength, m, for each specimen is calculated by

$$
\mathrm{m}=\frac{\mathrm{M}_{\mathrm{u}}}{\mathrm{f}_{\mathrm{cu}} \mathrm{bd}}
$$

Figure 5 shows the variation of normalized flexural strength with beam depth. As shown, there is no apparent size effect on the normalized ultimate flexural strength of the tested beams. Figure 6 plots the ductility factor varying with the depth of beams. For beams with symmetric longitudinal reinforcement, i.e. Specimens BC11, BC21 and $\mathrm{BC} 31$, the ductility factor decreases with increase of the depth of beams exhibiting a significant size effect. However, for beams with unsymmetric longitudinal reinforcement, i.e. Specimens BC22 and BC32, the size effect cannot be confirmed due to the insufficiency of test data. 


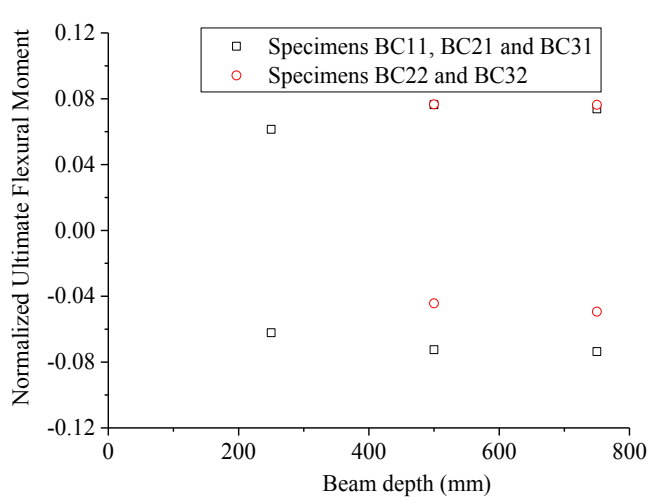

Figure 5 Normalized ultimate flexural moment

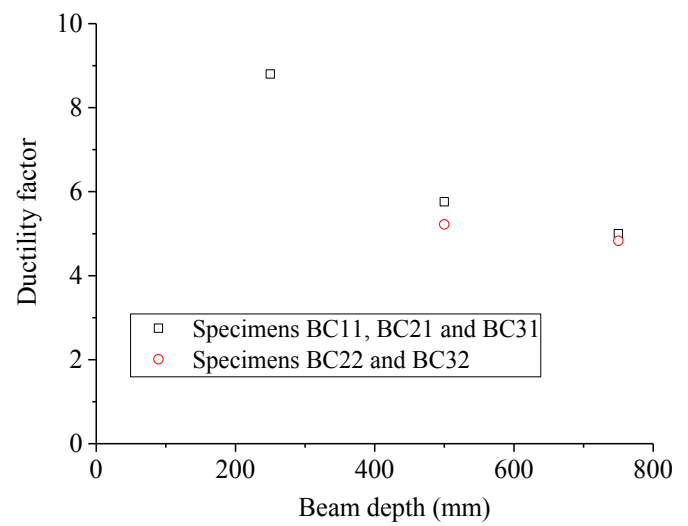

Figure 6 Ductility factor

\section{OpenSees Modeling}

\subsection{The FE Model}

Nonlinear analysis of the cyclic experiments was conducted by using OpenSees software which is based on fiber based finite element analysis. In the analysis, the

influence of shear deformation was considered, whereas the slippage of reinforcement was ignored.

The uniaxial material concrete 03 for concrete and the hysteretic model for reinforcement provided in OpenSees, as shown in figures 7 and 8, were used to simulate the nonlinear behavior of concrete and reinforcement, respectively. Detailed information of the FE models and the analysis of test specimens can be found elsewhere [13, 14].

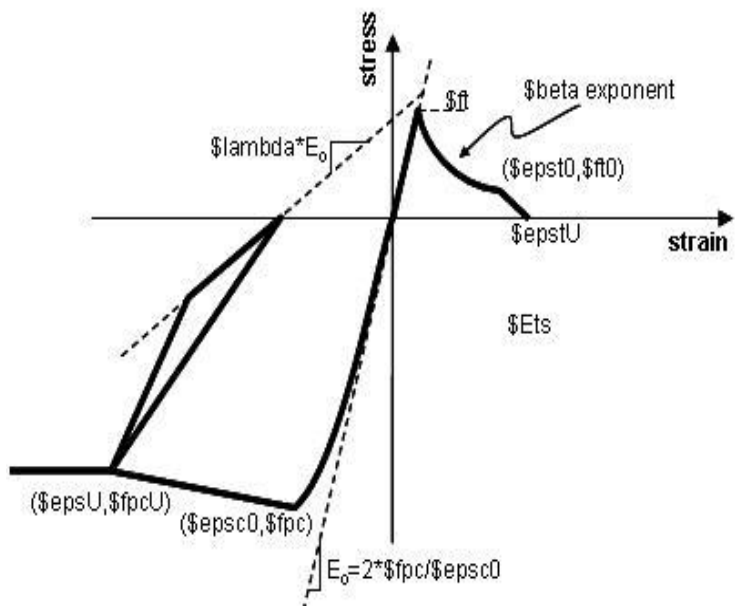

Figure 7 Concrete 02 model

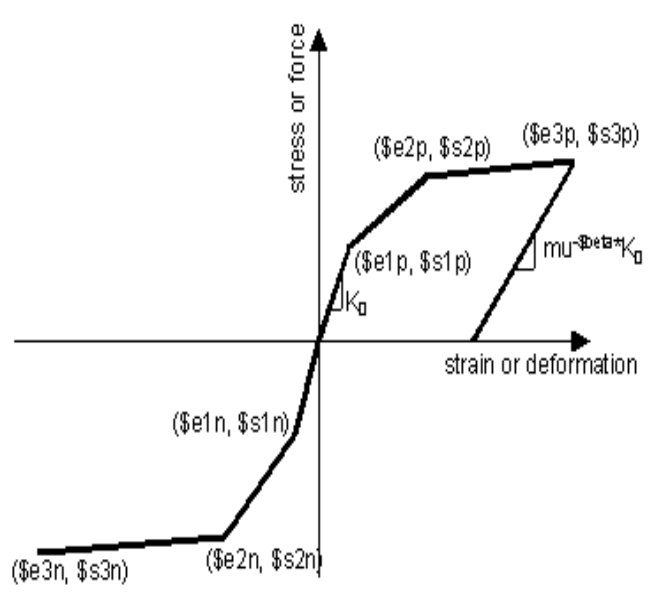

Figure 8 Hysteretic model

\subsection{Analytical Results and Comparison}

Figure 9 shows the load-deflection hysteric curves of Specimens BC11, BC21 and BC31obtained from the experiments and analysis by OpenSees. As can be seen, the results of the analysis are in good agreement with the experimental results, and the pinching effects of experimental curves are well captured by the FE analysis. The fiber-based element of OpenSees with Concrete03 model and Hysteric steel bar model is suitable to simulate cyclic behavior of RC beams and is able to consider the pinching effect. 


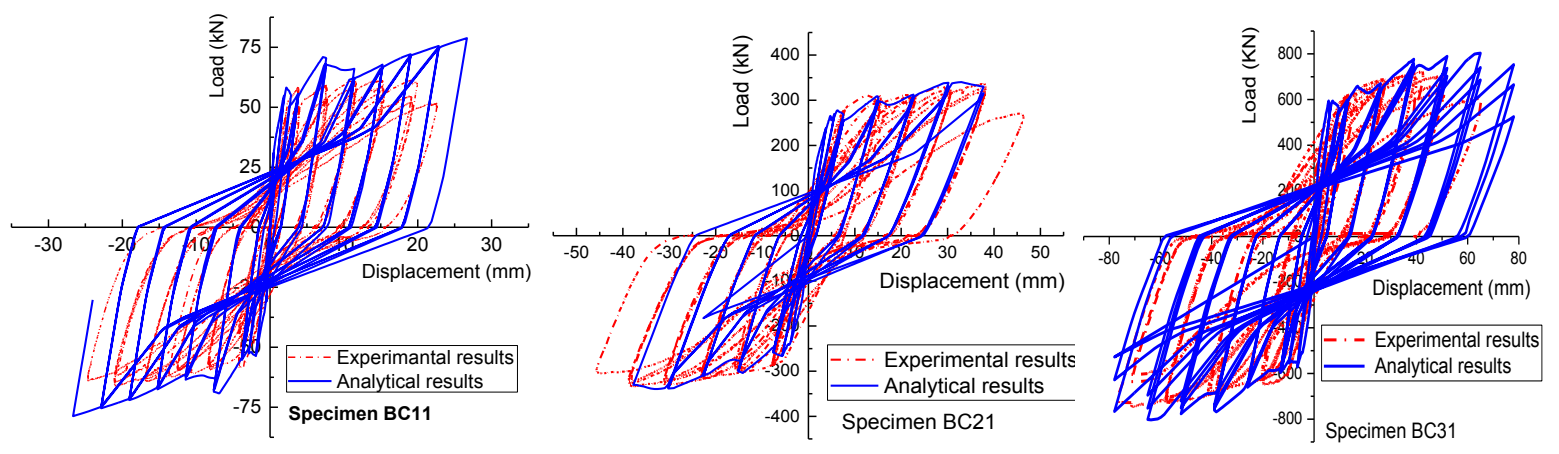

Figure 9 Comparison of load-deflection hysteric curves

\section{Conclusion}

Based on the present study, the following conclusions may be drawn:

(1) Test results show that there is no apparent size effect on the normalized ultimate flexural strength of the tested beams.

(2) For the displacement ductility factor, a significant size effect is observed experimentally in beams with symmetric reinforcement.

(3) The load-deflection hysteric curves obtained by the OpenSees analysis are in good agreement with those from experimental tests. It is found that the fiber-based element of OpenSees with Concrete03 and Hysteric models is suitable to simulate cyclic behavior of RC beams and is able to consider the pinching effect.

\section{Acknowledgement}

This research was financially supported by the Science Foundation of the State Key Laboratory of Costal and Offshore Engineering.

\section{References}

1. Bazant Z P and Planas J. Fracture and size effect in concrete and other quasibrittle materials $[\mathrm{M}]$. 1st ed., CRC Press, London, 1998.

2. Kim J K, Yi S T and Kim J H J. Effect of specimen sizes on flexural compressive strength of concrete $[\mathrm{J}]$. ACI Structural Journal, 2001, 98 (3): 416-424.

3. Corley W G. Rotational capacity of reinforced concrete beams, Journal of Structural Division [J]. 1966, 92 ST5: 121-146.

4. Alca N, Alexander S D B, and MacGregor J G. Effect of size on flexural behavior of high-strength concrete beams [J], ACI Structural Journal, 1997, 94 (1): 5967.

5. Appa R G, Vijayanand I and Eligehausen R. Studies on ductility and evaluation of minimum flexural reinforcement in RC beams [J]. Materials and Structures, 2008, 41: 759-771.

6. Yi S T, Kim M S, Kim J K and Kim J H J. Effect of specimen size on flexural compressive strength of reinforced concrete members $[\mathrm{J}]$. Cement and Concrete Composites, 2007, 29 (3): 230-40.

7. Bigaj A and Walraven J. Size effect in plastic hinges of reinforced concrete members [J]. Heron, 2002, 47 (1): 53-75.

8. Carpinteri A, Corrado M, Mancini G and Pagi M. Size-scale effect on plastic rotational capacity of reinforced concrete beams [J]. ACI Structural Journal, 2009, 106 (6): 887-895.

9. Khatieb M D. Experimental investigation of scale influence on plastic rotational capacity of reinforced concrete beams [J]. Engineering, 2016, 8:196-203.

10. Ozbolt J, Mestrovic D, Li Y and Eligehausen R. Compression failure of beams made of different concrete types and sizes [J]. Journal of Structural Engineering, 2000, 126 (2): 200-209.

11. Belgin $\mathrm{C} M$ and Şener S. Size effect on failure of overreinforced concrete beams [J]. Engineering Fracture Mechanics, 2008, 75(8): 2308-2319.

12. Vorel J, Gattu M and Bazant Z P. Size effect in flexure of prestressed concrete beams failing by compression softening [J]. Journal of Structural Engineering, 2014, 140 (10): 04014068.

13. S. Mazzoni, F. Mckenna, M. H. Scott, et al. OpenSees command language manual [R]. Pacific Earthquake Engineering Research (PEER) Center, 2007.

14. P. B. Malla P B. Nonlinear analysis of reinforced concrete based on Abaqus and OpenSees [D]. Dalian University of Technology, Dalian, China, 2016. 